\title{
The Use of the Patient Reported Outcomes Measurement Information System and the RAND VSQ9 to Measure the Quality of Life and Visit-Specific Satisfaction of Pregnant Patients Under Chiropractic Care Utilizing the Webster Technique
}

\author{
Joel Alcantara, DC, ${ }^{1,2}$ Andrea Lamont Nazarenko, $\mathrm{PhD}_{1}^{3,4}$ \\ Jeanne Ohm, DC, and Junjoe Alcantara, $\mathrm{DC}^{5}$
}

\begin{abstract}
Objective: To quantify the quality of life (QoL) and visit-specific satisfaction of pregnant women.

Design: A prospective cohort within a practice-based research network (PBRN).

Setting/Locations: Individual chiropractic offices.

Subjects: Pregnant women (age $\geq 18$ years) attending chiropractic care.

Intervention(s): Chiropractic care (i.e., The Webster Technique, spinal adjustments, and adjunctive therapies).

Main outcome measures: The RAND VSQ9 to measure visit-specific satisfaction and the Patient Reported Outcomes Measurement Information System (PROMIS ${ }^{\circledR}$ )-29 to measure QoL.

Results: A convenience sample of 343 pregnant patients (average age $=30.96$ years) comprised their study population. They were highly educated with $75 \%$ attaining a 2 -year associate's degree or higher. The pregnant patients presented for chiropractic care with a mean week of gestation of 25.67 weeks (median $=28$ weeks; range $=0-42$ weeks) and parity (i.e., the number of live births) of 0.92 live births (median $=1$; range $=0-6$ ). From baseline (i.e., at study entrance with minimum first visit) and comparative (i.e., following a course of chiropractic care), the VSQ9 measurements revealed increasingly high satisfaction on the part of the subjects (i.e., the mean difference of baseline minus comparative measures $=-0.7322 ; p<0.005$ ). The median number of visits (i.e., visits attended) at baseline and comparative measures was 1.00 (standard deviation $[\mathrm{SD}]=22.69)$ and $3.30(\mathrm{SD}=22.71)$, respectively. Across outcomes, QoL improved from baseline to comparative measurement after holding constant for visit number and time lapse, trimester of pregnancy, and care provider type. There was a reduction in mean $\mathrm{T}$ scores associated with fatigue $(p<0.05)$, pain interference $(p<0.05)$, sleep disturbance $(p<0.05)$, and an improvement in satisfaction with social roles $(p<0.05)$. A significant decrease was also found with pain interference $(p<0.05)$. No evidence was found that anxiety $(p=0.1404)$ or depression $(p=0.8785)$ changed.

Conclusion: A PBRN study was successfully implemented among chiropractors to find pregnant patients highly satisfied and their QoL scores improving with care beyond chance.
\end{abstract}

Keywords: chiropractic, pregnancy, quality of life, Webster Technique, PROMIS

\footnotetext{
${ }^{1}$ The International Chiropractic Pediatric Association, Media, PA.

${ }^{2}$ Department of Research, Life Chiropractic College West, Hayward, CA.

${ }^{3}$ Old Mill Chiropractic, LLC, Lexington, SC.

${ }^{4}$ Department of Psychology, University of South Carolina, Columbia, SC.

${ }^{5}$ Alcantara Chiropractic Philippines, Pasig City, PA.
}

(c) Joel Alcantara et al., 2017; Published by Mary Ann Liebert, Inc. This is an Open Access article distributed under the terms of the Creative Commons Attribution License, which permits unrestricted use, distribution, and reproduction in any medium, provided the original work is properly cited. 


\section{Introduction}

A CCORDING TO THE Centers for Disease Control and Prevention, the general fertility rate for the United States in 2013 was 62.5 births per 1000 women aged 15-44 years based on 3,932,181 registered births. ${ }^{1}$ During pregnancy, the expectant mother is faced with many physiologic and biomechanical changes that affect her emotional, physical, and mental well-being. Complementary and alternative medicine (CAM) is popular for women of childbearing age with prior use as the most significant independent associated factor for CAM use during pregnancy. ${ }^{2,3} \mathrm{~A}$ review of the literature on the use of CAM by pregnant women found varying estimates from $1 \%$ to $87 \%$. ${ }^{4}$ CAM use was to address a variety of complaints such as pregnancy-related musculoskeletal (MSK) pain, nausea and vomiting, problems with labor, postpartum perineal discomfort, lactation disorders, as well as to fulfill their spiritual and emotional needs. ${ }^{2,5-7}$

Of the various practitioner-based CAM therapies, chiropractic has been shown to be popular among women before, during, and after their pregnancy. ${ }^{8}$ Chiropractic's holistic and vitalistic paradigm of care and its effectiveness in addressing the myriad of MSK complaints during pregnancy ${ }^{9,10}$ make it an attractive CAM option for pregnant women. ${ }^{11,12}$

As with all healthcare providers (i.e., conventional or alternative), chiropractors must implement and demonstrate effective healthcare interventions throughout a woman's pregnancy, as well as during the postpartum period. There is anecdotal evidence indicating that pregnant women report improved quality of life (QoL) after receiving chiropractic care. Given societal problems related to overreliance on drugs (e.g., opioids) ${ }^{13}$ and high rates of postpartum depression and anxiety, ${ }^{14}$ there is a need to explore alternative solutions to improving maternal QoL. Toward these efforts and in the interest of evidence-informed practice, the authors examined the QoL and visit-specific satisfaction of pregnant women undergoing chiropractic care in a practicebased research network (PBRN). In particular, the authors aimed to: (1) better understand the population of pregnant women seeking chiropractic care during pregnancy; and (2) understand whether these women report less problems with emotional disturbances (i.e., depression, anxiety), sleep disturbance, fatigue, pain, and physical functioning before after receiving chiropractic care.

\section{Methods}

This study was approved by the Institutional Review Board of Life University (Marietta, GA). An e-mail invitation was sent out to Doctors of Chiropractic (DC) previously or currently enrolled in a postgraduate course offered by the International Chiropractic Pediatric Association (ICPA) ${ }^{15}$ to participate in a PBRN study to characterize the chiropractic care of pregnant patients utilizing the Webster Technique. ${ }^{16}$ The technique involves a specific chiropractic analysis and the application of a chiropractic adjustment to the sacrum along with soft-tissue work. A sustained thumb contact is then applied to a specific point on the patient's belly to release tension in the corresponding uterine ligament. The goal with this approach is to reduce the consequences of sacral subluxation (i.e., P-L sacrum or $+\theta Y$; P-R sacrum or $-\theta \mathrm{Y}$ ) to improve the functional integrity of the pelvic bowl with a developing fetus.
As in previous studies implementing this $\mathrm{PBRN},{ }^{17-20}$ inclusion criteria for DC participation include: (1) the DC must be in good standing with their licensing authority; (2) completed the National Institute of Health online course entitled, "Protecting Human Research Participants",21; (3) agreed to a number of terms for participation as an ICPA PBRN participant-most notably that PBRN participation must not be used for practice building or marketing; and (4) the Webster Technique ${ }^{16}$ was implemented as part of the care in the presenting pregnant patient. The participating DCs were encouraged to invite their patients as respondents for this study. Patient participation as responders in this study included the following criteria: (1) the patient was at least 18 years of age; (2) informed consent was agreed upon for study participation; and (3) the responder was pregnant during the course of the study.

\section{Patient survey}

In addition to acquiring sociodemographic information (i.e., age, gender, and level of education) and clinical correlates of the history and physical examination (i.e., primary presenting complaints and previous care strategies) from the subjects, the authors utilized as primary outcome measures the RAND VSQ9 ${ }^{22}$ and the Patient Reported Measurement Information System (i.e., PROMIS ${ }^{\circledR}-29$ V1) ${ }^{23}$ questionnaires to measure the subjects' visit-specific satisfaction and QoL, respectively. The RAND VSQ9 ${ }^{22}$ is a 9-item questionnaire adapted by the American Medical Group ${ }^{24}$ from the Visit Rating Questionnaire used in the RAND Medical Outcomes Study. ${ }^{25}$ The PROMIS-29 is a 29-item profile instrument consisting of a fixed collection of short forms to measure emotional distress (i.e., anxiety and depression), fatigue, pain interference and intensity (i.e., $0=$ no pain; $10=$ worst imaginable pain), physical functioning, sleep disturbance, and satisfaction with participation in social roles. Patient responders were either existing patients (i.e., currently receiving care) or new patients (i.e., attended less than one to two patient visits). Baseline (i.e., survey completed upon study entrance) and comparative (i.e., survey completed following a course of care) measures utilizing these two survey instruments were implemented before and following a course of chiropractic care. The survey instruments were pilot tested with 10 respondents and implemented as a paper-and-pencil questionnaire without difficulty.

\section{Statistical analysis}

The VSQ9 and PROMIS-29 data were entered into an online data processing center created specifically for the purpose of this study and exported to an Excel spreadsheet (Microsoft Corporation, Portland, OR) for analysis. The sociodemographic data were analyzed using descriptive statistics. The VSQ9 questions were prefaced with "Thinking about your visit with the physician/healthcare professional you saw, how would you rate ..." with responses utilizing a five-level scale that were linearly transformed (i.e., poor $=0 \%$; fair $=$ $25 \%$; $\operatorname{good}=50 \%$; very $\operatorname{good}=75 \%$; and excellent $=100 \%$ ). These were also analyzed with descriptive statistics. These were provided as frequencies and percentages, means, and standard deviations (SDs). Mean difference between baseline and comparative measures of the VSQ9 was also analyzed using the paired $t$ test. The PROMIS-29 data were analyzed 
using the PROMIS Assessment Center ${ }^{\text {SM }}, 26$ a free online data collection tool to securely capture participant data and provide real-time scoring. For each PROMIS short form (i.e., anxiety, physical functioning, and pain interference), a scoring table was developed to associate the raw scores to a T score metric, which was referenced to (and centered upon) the U.S. General population $^{27}$ with a mean of 50 and SD of 10 . The greater the $\mathrm{T}$ score, the greater the measured QoL domain.

Due to distributional differences across outcomes, two different statistical models were applied to address the question: Did self-reported QoL measures among pregnant women improve in women under chiropractic care from baseline to comparative? The authors tested seven different domains of QoL: anxiety, depression, physical functioning, sleep disturbance, satisfaction with participation in social roles, pain interference, and fatigue. All data were nested within individuals and chiropractic offices since QoL reports at baseline and comparative were more similar within a person than across people and more similar among patients of the same office than different offices (i.e., more between than within variation in the outcome). Thus, the authors took this between-office variation into account using a random effects framework. Results can be interpreted as the change in QoL symptoms from baseline to follow-up independent of the chiropractor.

Using the notation of Raudenbush and Bryk, ${ }^{28}$ the following equations were estimated.

Level 1: within subject

$$
\begin{aligned}
\mathrm{Y}_{\mathrm{tij}}= & \pi_{0 \mathrm{ij}}+\pi_{1 \mathrm{ij}}(\text { Time })_{\mathrm{tij}}+\pi_{2 \mathrm{ij}}(\text { Visit Lapse })_{\mathrm{tij}} \\
& +\pi_{3 \mathrm{ij}}(\text { Visit Number })_{\mathrm{tij}}+\pi_{4 \mathrm{ij}}(\text { Nurse-Midwife })_{\mathrm{tij}} \\
& +\pi_{5 \mathrm{ij}}(\mathrm{OB})_{\mathrm{tij}}+\pi_{6 \mathrm{ij}}(\text { Other Provider })_{\mathrm{tij}} \\
& +\pi_{7 \mathrm{ij}}(\text { Trimester })_{\mathrm{tij}}+\mathrm{e}_{\mathrm{tij}}
\end{aligned}
$$

Level 2: between subject

$$
\begin{gathered}
\pi_{0 \mathrm{j}}=\beta_{00 \mathrm{j}}+\mathrm{r}_{0 \mathrm{ij}}, \\
\pi_{1 \mathrm{j}}=\beta_{10 \mathrm{j}}+\mathrm{r}_{1 \mathrm{ij}}, \\
\pi_{2 \mathrm{j}}=\beta_{20 \mathrm{j}}, \\
\pi_{3 \mathrm{j}}=\beta_{30 \mathrm{j}}, \\
\pi_{4 \mathrm{j}}=\beta_{40 \mathrm{j}}, \\
\pi_{5 \mathrm{j}}=\beta_{50 \mathrm{j}}, \\
\pi_{6 \mathrm{j}}=\beta_{60 \mathrm{j}}
\end{gathered}
$$

Level 3: between DC

$$
\begin{gathered}
\beta_{00 \mathrm{j}}=\gamma_{000}+\mathrm{u}_{00 \mathrm{j}}, \\
\beta_{10 \mathrm{j}}=\gamma_{100}, \\
\beta_{20 \mathrm{j}}=\gamma_{200}, \\
\beta_{30 \mathrm{j}}=\gamma_{300},
\end{gathered}
$$

$$
\begin{aligned}
& \beta_{40 \mathrm{j}}=\gamma_{400}, \\
& \beta_{50 \mathrm{j}}=\gamma_{500}, \\
& \beta_{60 \mathrm{j}}=\gamma_{600}, \\
& \beta_{70 \mathrm{j}}=\gamma_{700},
\end{aligned}
$$

where the parameter of interest is $\pi_{1}$, representing the change in the outcome from baseline to comparison. Visit lapse (i.e., defined as the number of visits between baseline and comparative QoL ratings), visit number (i.e., defined as the number of chiropractic visits the patient received before baseline), trimester of pregnancy, and provider type (i.e., with midwife as the reference group, compared to nursemidwife, OB/GYN, and other provider) were added in as covariates. All covariates were grand mean centered.

Three QoL domains (i.e., anxiety, depression, and physical functioning) were highly skewed leading to significant violations of distributional assumptions of linear models. These outcomes were therefore dichotomized and tested in a generalized linear model framework (logit link function). This was the most logical approach given the particular distribution (i.e., preponderance of zeros) and the meaningfulness of the scale values (e.g., the difference between having one or two symptoms was not clinically meaningful, but having no versus any symptoms was very meaningful). A Wald test was used to test whether the proportion of respondents endorsing any symptoms of anxiety, depression, and physical functioning significantly changed from baseline to comparative measurement, after conditioning on a set of covariates (i.e.,visit lapse, visit number, trimester of pregnancy and provider type). In conceptualizing the rate of type I errors due to multiple comparisons, the False Discovery Rate was held at $p=0.05$. All analyses were conducted in Mplus version 7.29 Differences across chiropractic offices were taken into account through the inclusion of a random intercept term in all models.

\section{Results}

\section{Who are the women seeking chiropractic care?}

A convenience sample of 343 pregnant patients participated in the study. Their average age was 30.96 years $(\mathrm{SD}=4.64)$. This cohort of subjects was highly educated with the vast majority attaining a college education or above (i.e., 2-year associate's degree $[N=31 ; 9 \%]$; baccalaureate $[N=152 ; 44 \%]$; masters $[N=68 ; 20 \%]$; PhD $[N=9 ; 3 \%])$, while the remainder received some college education $(N=63 ; 18 \%)$ or graduated from high school $(N=18 ; 5 \%)$ with $2(<1 \%)$ nonresponders.

The pregnant patients presented for chiropractic care, on average, in their 25th week of gestation $(\mathrm{SD}=9.84)$ with an average parity (i.e., number of live births) of $0.92(\mathrm{SD}=1.0)$. Forty-five $(13.1 \%)$ were in their 1st trimester, $113(32.9 \%)$ were in their 2nd trimester, and 185 (53.9\%) were in their 3rd trimester of pregnancy.

The vast majority indicated as their primary provider an OB/GYN $(N=197 ; 57 \%)$ followed by a midwife (nursemidwife $[N=32 ; 9 \%]$; midwife $[N=94 ; 27 \%]$; a medical doctor $[N=11 ; 3 \%]$; and "other" $[N=9 ; 3 \%]$. Of the 9 [3\%] indicating "other" as their primary provider, 4 [1\%] 
Table 1. Baseline and Comparative Scoring of the RAND VSQ9

\begin{tabular}{|c|c|c|c|c|}
\hline & \multicolumn{2}{|c|}{ Baseline } & \multicolumn{2}{|c|}{ Comparative } \\
\hline & Mean & $S D$ & Mean & $S D$ \\
\hline 1. How long you waited to get an appointment? & 93.62 & 13.91 & 95.1 & 11.82 \\
\hline 2. Convenience of the location of the office? & 84.94 & 22.69 & 85.16 & 21.1 \\
\hline 3. Getting through the office by phone? & 91.77 & 15.7 & 93.4 & 13.33 \\
\hline 4. Length of time waiting at the office? & 90.73 & 16.4 & 91.84 & 14.82 \\
\hline 5. Time spent with the physician/healthcare professional you saw? & 93.47 & 12.72 & 94.51 & 11.87 \\
\hline 6. Explanation of what was done to you? & 93.62 & 12.65 & 94.14 & 12.24 \\
\hline $\begin{array}{l}\text { 7. Technical skills (thoroughness, carefulness, and competence) } \\
\text { of the physician/ healthcare professional you saw? }\end{array}$ & 95.62 & 9.90 & 96.22 & 9.57 \\
\hline $\begin{array}{l}\text { 8. The personal manner (courtesy, respect, sensitivity, and friendliness) } \\
\text { of the person you saw? }\end{array}$ & 97.48 & 7.54 & 97.26 & 8.30 \\
\hline 9. The visit overall? & 95.62 & 10.27 & 96.14 & 9.25 \\
\hline
\end{tabular}

$\mathrm{SD}$, standard deviation.

indicated having an $\mathrm{OB} / \mathrm{GYN}$ as their secondary provider while $1[<1 \%]$ ) indicated a midwife in this role.

Three quarters of the patients $(N=258 ; 75 \%)$ indicated that their primary provider was aware of their consultation and care with a chiropractor. This includes women $(N=48 ; 14 \%)$ who reported that their provider was aware and referred them to chiropractic. The referral came from midwives $(N=28$; $8 \%)$ followed by nurse-midwife $(N=11 ; 3 \%)$, obstetrician/ gynecologists $(N=7 ; 2 \%)$, and medical physicians $(N=2$; $<1 \%$ ). There was a significant relationship between the provider type and knowledge of chiropractic, such that midwives and nurse-midwives were more likely to know and have referred than OB/GYNs $\left(\chi^{2}=53.975, \mathrm{df}=6, p<0.0001\right)$.

In terms of motivation for care, $88 \%(N=302)$ reported receiving chiropractic for MSK symptoms, 59\% $(N=202)$ reported chiropractic for wellness, and $41 \%$ reported both MSK and wellness as reasons for care. The reported motivation for care was not necessarily mutually exclusive. Note that for those presenting with an MSK complaint, 41\% $(N=124)$ presented for wellness care while $36 \%(N=108)$ did not. For those presenting without an MSK complaint, $18 \%(N=62)$ presented for wellness while $6 \%(N=20)$ did not. Specific to the MSK complaints, the following were indicated: low back pain $(N=96 ; 28 \%)$, leg pain $(N=18 ; 5 \%)$, mid-back pain $(N=16 ; 4 \%)$, neck pain $(N=4 ; 1 \%)$, and shoulder pain $(N=4 ; 1 \%)$. One hundred and ninety-six $(57 \%)$ indicated "Other" as a response. An analysis of the $196(57 \%)$ motivated as "Other" found them to consist of multiple symptom areas with low back pain as the most common accompanying complaints (i.e., low back pain and neck pain or low back pain and shoulder pain; $N=168 ; 49 \%$ ), while 20 (6\%) indicated multiple areas of complaint but not involving the low back. One-fifth $(20.4 \% ; N=58)$ of the women also reported receiving care outside of chiropractic. The most popular alternative care was self-care exercises $(26.8 \% ; N=$ 92). Seven percent $(N=24)$ also reported over-the-counter medications, $8 \%(N=27)$ reported seeing another DC, and 6\% $(N=20)$ received nutrition guidance. Three percent $(N=10)$ used herbal products, acupuncture, and MD care.

The results for the baseline and comparative VSQ9 survey are presented in Table 1. The median number of patient visits (i.e., visits attended) at baseline was $1.00(\mathrm{SD}=22.69)$ and at comparative measurement was $3.00(\mathrm{SD}=22.71)$. Overall, visit-specific satisfaction was high among the responders at baseline and comparative measurement. At baseline, the mean percent score ranged from $84.94(\mathrm{SD}=22.69$; i.e., convenience of the office location) to 97.48 ( $\mathrm{SD}=7.54$; i.e., courtesy, respect, and friendliness of DC). When examining the comparative VSQ9 scoring, the authors observe similar trends as baseline but more importantly, the satisfaction ratings have increased. A paired $t$ test of the mean VSQ9 scores at baseline and comparative revealed this increase to be statistically significance $(t=3.8409 ; \mathrm{df}=8 ; p<0.005)$.

\section{Did the women report improved QoL from baseline to comparative time points?}

The mean $\mathrm{T}$ scores for baseline and comparative measures with respect to the QoL domains are shown in Table 2. The mean baseline and comparative pain numerical rating scale (NRS) were 4.09 and 3.23, respectively. This reduction in pain NRS scores was found to be statistically significant based on a paired $t$ test analysis $(t=9.05 ; \mathrm{df}=342 ; p<0.0001)$. With respect to the question of whether self-reported QoL among the pregnant women improved from baseline to comparative, results showed that there was a significant increase in QoL based on most of the QoL domains, after holding constant for visit number and time lapse, trimester of pregnancy, and care provider type (Tables 3-6). There was a reduction in mean T scores associated with fatigue $(\beta=-2.19$, standard error of the

Table 2. Baseline and Comparative Mean t Scores FROM THE PROMIS-29

\begin{tabular}{|c|c|c|c|c|c|}
\hline \multirow[b]{2}{*}{ Domain } & \multicolumn{2}{|c|}{ Baseline } & \multicolumn{2}{|c|}{ Comparative } & \multirow{2}{*}{$\begin{array}{c}\begin{array}{c}\text { Rothrock } \\
\text { et al. }{ }^{44}\end{array} \\
\text { Mean } \\
\text { T Score }\end{array}$} \\
\hline & $\begin{array}{l}\text { Mean } \\
\text { T Score }\end{array}$ & $S D$ & $\begin{array}{c}\text { Mean } \\
\text { T Score }\end{array}$ & $S D$ & \\
\hline $\begin{array}{l}\text { Physical } \\
\text { functioning }\end{array}$ & 45.26 & 7.38 & 45.85 & 7.36 & 51 \\
\hline Anxiety & 49.2 & 7.75 & 47.28 & 7.53 & 48 \\
\hline Depression & 44.82 & 5.81 & 44.1 & 5.36 & 48 \\
\hline Fatigue & 55.25 & 7.53 & 53.06 & 7.89 & 47 \\
\hline $\begin{array}{l}\text { Sleep } \\
\text { disturbance }\end{array}$ & 51.65 & 6.76 & 50.23 & 7.01 & - \\
\hline $\begin{array}{l}\text { Satisfaction with } \\
\text { social roles }\end{array}$ & 47.97 & 8.57 & 49.52 & 8.18 & 52 \\
\hline Pain interference & 55.03 & 8.27 & 52.33 & 7.96 & 49 \\
\hline
\end{tabular}


Table 3. Statistical Analysis for Sleep DisTURBANCE UTILIZING A 3-LEVEL GENERALIZED LiNEAR MODEL

\begin{tabular}{|c|c|c|c|c|c|}
\hline $\begin{array}{l}\text { Sleep } \\
\text { disturbance }\end{array}$ & Value & $S E M$ & $d f$ & $\mathrm{t}$ & $\mathrm{p}$ \\
\hline (Intercept) & 47.19073 & 1.36974 & 326 & 34.45233 & 0 \\
\hline $\begin{array}{l}\text { Duration of } \\
\text { symptoms }\end{array}$ & -1.35838 & 0.38472 & 326 & -3.53081 & 0.0005 \\
\hline Visit lapse & -0.20339 & 0.173267 & 269 & -1.17386 & 0.2415 \\
\hline Visit No. & -0.00682 & 0.015724 & 269 & -0.4339 & 0.6647 \\
\hline $\begin{array}{l}\text { Trimester of } \\
\text { pregnancy }\end{array}$ & 2.02452 & 0.471752 & 269 & 4.29148 & 0 \\
\hline $\begin{array}{l}\text { Provider } \\
\text { (nurse- } \\
\text { midwife) }\end{array}$ & 0.21483 & 1.239965 & 269 & 0.17325 & 0.8626 \\
\hline $\begin{array}{l}\text { Provider } \\
\text { (OB/GYN) }\end{array}$ & -0.78101 & 0.784949 & 269 & -0.99498 & 0.3206 \\
\hline $\begin{array}{l}\text { Provider } \\
\text { (other) }\end{array}$ & -1.01217 & 1.548169 & 269 & -0.65379 & 0.5138 \\
\hline
\end{tabular}

SEM, standard error of the mean.

mean $[\mathrm{SEM}]=0.44)$, pain interference $(\beta=-2.64, \mathrm{SEM}=$ $0.46)$, and sleep disturbance $(\beta=-1.36, \mathrm{SEM}=0.43)$ and an increase in mean $\mathrm{T}$ scores for satisfaction with participation in social roles $(\beta=1.58, \mathrm{SEM}=0.43)$. Beta coefficients represent the change in the outcome across one unit of time (baseline to comparison), after holding all possible confounders constant. As expected, across outcomes, advanced trimester worsened QoL, consistent with patient reports of physical complaints as pregnancy progresses. For dichotomous models, they found a significant decrease in mean $\mathrm{T}$ scores for pain interference from baseline to comparative, after controlling for covariates (Wald $=12.280, \mathrm{df}=1, p=0.0005$ ). The authors did not find evidence that there was a change in mean $\mathrm{T}$ scores for anxiety $(\mathrm{Wald}=2.174, \mathrm{df}=1, p=0.1404$ ) or depression (Wald $=0.023, \mathrm{df}=1, p=0.8785$ ) from baseline to comparative measurement.

\section{Discussion}

Chiropractic has been suggested as an alternative solution for problems related to low QoL, ${ }^{30}$ but has not yet been studied in the empirical literature. This is the first study to systematically evaluate the changes in a number of domains of QoL among pregnant women. Understanding the characteristics and reasons that women seek chiropractic care during pregnancy and the changes they report in their QoL with care is an integral step in understanding this alternative and low risk strategy for healthcare. The purpose of this study was to understand the characteristics and reasons why women seek chiropractic care and to test whether the changes in QoL observed after starting chiropractic care were greater than the changes they would expect based on chance alone. The results show that women who seek chiropractic care during pregnancy are well educated and under care with other birthing professionals, most often OB/GYNs. Women sought chiropractic care most often for MSK issues and wellness care and communicated their treatment with other care providers, especially with midwives (vs. traditional OB/GYN care). One possible reason for this is the expectation that midwives will be more supportive of chiropractic care than an MD and suggests that more work is needed to bridge alternative and traditional healthcare options. As this was a normative population, most women presented with fairly good QoL across domains, but variability existed. Over the course of chiropractic care, women reported improvements in QoL domains that would otherwise be considered stable in the short term, lending support to the theory that chiropractic care contributed to these improvements.

This study adds to the growing evidence that suggests that chiropractic care may play a role in QoL and overall wellness, beyond MSK conditions. There is strong theoretical reason to believe that spinal adjustments and correction of vertebral subluxation improve nerve system function and therefore a function of the person as a whole. Studies have demonstrated that chronic pain contributes to disability, anxiety, depression, sleep disturbances, poor QoL, and healthcare costs. ${ }^{31}$ By relieving physical distress and restoring the body's natural way of functioning, chiropractic may play a key role in the improvement of QoL. Future researchers should continue to examine the role of chiropractic care on QoL outcomes to understand the precise mechanisms on which the outcomes are achieved. This is particularly important for the care of pregnant women who are more likely to experience MSK problems as part of pregnancy and seek safe treatment solutions. This study contributes to a growing body of literature that suggests that chiropractic care may be an alternative strategy to traditional pharmaceuticals to manage this discomfort and improve QoL. Improvements in QoL for pregnant women, in particular, are a critical area for future research, given risks associated with postpartum distress and tendency to rely on opioid solutions for pain relief.

Table 4. Statistical Analysis for Satisfaction with Participation in Social Role Utilizing a 3-Level Generalized Linear Model

\begin{tabular}{|c|c|c|c|c|c|}
\hline $\begin{array}{l}\text { Satisfaction with participation } \\
\text { in social role }\end{array}$ & Value & SEM & $d f$ & $\mathrm{t}$ & $\mathrm{p}$ \\
\hline (Intercept) & 50.25268 & 1.724265 & 326 & 29.14442 & 0 \\
\hline Duration of symptoms & 1.58089 & 0.434462 & 326 & 3.638739 & 0.0003 \\
\hline Visit lapse & -0.40935 & 0.214018 & 269 & -1.91271 & 0.0568 \\
\hline Visit No. & 0.02658 & 0.019395 & 269 & 1.370265 & 0.1717 \\
\hline Trimester of pregnancy & -1.2002 & 0.592103 & 269 & -2.02701 & 0.0436 \\
\hline Provider (nurse-midwife) & -1.12148 & 1.553922 & 269 & -0.72171 & 0.4711 \\
\hline Provider $(\mathrm{OB} / \mathrm{GYN})$ & 1.24745 & 0.978137 & 269 & 1.275331 & 0.2033 \\
\hline Provider (other) & -0.54979 & 1.935274 & 269 & -0.28409 & 0.7766 \\
\hline
\end{tabular}


Table 5. Statistical Analysis for Pain INTERFERENCE UTILIZING A 3-LEVEL GENERALIZED LINEAR MODEL

\begin{tabular}{|c|c|c|c|c|c|}
\hline $\begin{array}{l}\text { Pain } \\
\text { interference }\end{array}$ & Value & SEM & $d f$ & $\mathrm{t}$ & $\mathrm{p}$ \\
\hline (Intercept) & 53.11482 & 1.653561 & 326 & 32.12147 & 0 \\
\hline $\begin{array}{l}\text { Duration of } \\
\text { symptoms }\end{array}$ & -2.63597 & 0.462653 & 326 & -5.6975 & 0 \\
\hline Visit lapse & 0.40792 & 0.210559 & 269 & 1.93731 & 0.0538 \\
\hline Visit No. & -0.00928 & 0.019146 & 269 & -0.48485 & 0.6282 \\
\hline $\begin{array}{l}\text { Trimester of } \\
\text { pregnancy }\end{array}$ & 1.11615 & 0.561265 & 269 & 1.98863 & 0.0478 \\
\hline $\begin{array}{l}\text { Provider } \\
\text { (nurse- } \\
\text { midwife) }\end{array}$ & 0.46665 & 1.478385 & 269 & 0.31565 & 0.7525 \\
\hline $\begin{array}{l}\text { Provider } \\
\text { (OB/GYN) }\end{array}$ & -1.34345 & 0.943001 & 269 & -1.42465 & 0.1554 \\
\hline $\begin{array}{l}\text { Provider } \\
\text { (other) }\end{array}$ & -2.50531 & 1.852041 & 269 & -1.35273 & 0.1773 \\
\hline
\end{tabular}

\section{Pregnancy and chiropractic care}

Since chiropractic's inception, the care of pregnant women has been an integral part of the practice of chiropractic. ${ }^{32} \mathrm{~A}$ popular approach to pregnancy care has been the use of the Webster Technique. ${ }^{16}$ The technique involves a specific chiropractic analysis and the application of a chiropractic adjustment along with soft-tissue work. The goal with this approach is to reduce the consequences of sacral subluxation and improve the functional integrity of the pelvic bowl with a growing fetus. Despite extensive clinical experience and empirical data in the care of pregnant women, a systematic review of the literature by Stuber and Smith ${ }^{33}$ on chiropractic's effectiveness for pregnancy care consists only of low-to-moderate quality evidence. Since the published review by Stuber and $\mathrm{Smith}^{33}$ in 2008, further support of chiropractic's effectiveness in the care of pregnant women has been published. Noteworthy was the study by Peterson et al. ${ }^{34}$ These investigators reported outcomes in pregnant patients with low back or pelvic pain under chiropractic care using the patient's global impression of change (PGIC), the NRS, and the Oswestry collected at 1 week, 1 and 3 months

Table 6. Statistical Analysis for Fatigue Utilizing a 3-Level Generalized Linear Model

\begin{tabular}{lccccc}
\hline Fatigue & Value & SEM & $d f$ & $\mathrm{t}$ & $\mathrm{p}$ \\
\hline $\begin{array}{l}\text { (Intercept) } \\
\text { Duration of } \\
\text { symptoms }\end{array}$ & -2.185556 & 0.561678 & 326 & 34.93425 & 0 \\
$\begin{array}{c}\text { Visit lapse } \\
\text { Visit No. }\end{array}$ & 0.16938 & 0.205228 & 269 & 0.82533 & 0.4099 \\
$\begin{array}{c}\text { Trimester of } \\
\text { pregnancy }\end{array}$ & 0.34366 & 0.018705 & 269 & 1.28374 & 0.2003 \\
$\begin{array}{c}\text { Provider } \\
\text { (nurse- }\end{array}$ & 0.77571 & 1.400611 & 269 & 0.55384 & 0.5801 \\
$\begin{array}{c}\text { midwife) } \\
\text { Provider } \\
\quad \text { (OB/GYN) }\end{array}$ & -0.25288 & 0.901807 & 269 & -0.28042 & 0.7794 \\
$\begin{array}{c}\text { Provider } \\
\text { (other) }\end{array}$ & -0.19591 & 1.761256 & 269 & -0.11123 & 0.9115 \\
\hline
\end{tabular}

after initiating care. The investigators found that $52 \%$ of 115 recruited patients "improved" at 1 week, $70 \%$ at 1 month, $85 \%$ at 3 months, $90 \%$ at 6 months, and $88 \%$ at 1 year based on significant reductions in NRS and Oswestry scores. George et al. ${ }^{35}$ performed a prospective randomized trial of 169 women receiving either a multimodal approach of chiropractic (i.e., manual therapy, stabilization exercises, and patient education) and obstetric management or standard obstetric care alone to reduce pain, impairment, and disability in the antepartum period. Baseline evaluation at 24-28 weeks gestation and comparative at 33 weeks gestation utilizing the pain NRS and the Quebec Disability Questionnaire (QDQ) were performed. Those receiving a combination of chiropractic and standard obstetrics care demonstrated significant mean reductions in NRS scores and QDQ scores from baseline to comparative evaluation. The group receiving standard obstetric care demonstrated no significant improvements.

Patient reported outcomes or PROs play an important role in healthcare and healthcare research in that they measure or reflect the impact of a disease or condition on the individual patient. However, Eton et al. ${ }^{36}$ lamented that there are two pressing issues on the use of PROs in CAM therapy and research. One, there is a lack of guidance for selecting PRO measures and two, there is limited attention paid to the clinical meaningfulness of the PRO results. Eton et al. ${ }^{36}$ recommended the use of PROMIS to support selection and standardization of PROs for CAM research. Mogos et al. ${ }^{37}$ reviewed the use of QoL measures during pregnancy and the postpartum period and found that valid, reliable, and responsive PRO instruments are lacking. Their analysis of the existing measurement scales revealed important validity, reliability, and psychometric inadequacies making their use in comparative effectiveness research challenging. Specific to pregnancy care under chiropractic, Alcantara et al. ${ }^{38}$ published their findings on the systematic review of the literature on the use of validated outcome measures for the care of pregnant patients. The authors found in eight articles the use of the PGIC, the pain NRS, the Oswestry, Bournemouth, Fear Avoidance Belief and QDQ questionnaires, PROMIS-29, and the Measure Yourself Medical Outcome Profile. The use of PROMIS-29 involved a limited sample size involving a case series of six patients. ${ }^{39}$ Although the review found some measure of effectiveness in the chiropractic care of pregnant patients, Alcantara et al. ${ }^{38}$ concluded that given the heterogeneity and inconsistency of use of these outcome measures, cause and effect inferences for true measures of effectiveness in chiropractic pregnancy care were severely limited. Others have made similar conclusions on the use of validated outcome measures on chiropractic patients in general. ${ }^{40,41}$

Funded by the National Institute of Health, PROMIS provides researchers and clinicians with psychometrically sound and clinically meaningful measurement system of a patient's reported outcome. In addition to their reliability and validity, the PROMIS instruments have comparability (i.e., the measures have been standardized so that there are common domains and metrics across conditions that facilitate comparisons across domains and diseases), flexibility (i.e., PROMIS can be administered in a variety of ways, in different forms), and inclusiveness (i.e., PROMIS encompasses all people, regardless of literacy, language, physical function, 
or life course). ${ }^{42}$ Their use of the PROMIS-29 instrument demonstrated statistically significant changes in mean $\mathrm{T}$ scores from baseline to comparative measures suggesting that overall, the QoL of pregnant patients under chiropractic care improved. There was a reduction in mean $\mathrm{T}$ scores associated with fatigue, pain interference, and sleep disturbance and an increase in mean $\mathrm{T}$ scores in satisfaction with participation in social roles following a course of chiropractic care. However, the authors did not have evidence that anxiety and depression changed. With respect to the mean pain NRS scores from baseline to comparative despite findings of a statistically significant decrease, this decrease was not clinically significant as per Farrar et al. ${ }^{43}$ According to Farrar et al., ${ }^{43}$ a 2-point improvement is clinically meaningful on an 11-point pain scale as that utilized in their study. Despite findings by others on clinically meaningful changes in pain NRS scores among pregnant patients under chiropractic care ${ }^{37}$ the authors did not find similarly. These disparate findings with the pain NRS deserve further investigation particularly when they observed statistically significant decrease in pain interference with a trial of chiropractic care. To the best of their knowledge, this is the first reporting in the scientific literature on the characterization of a large cohort of pregnant patients undergoing chiropractic care using the PROMIS questionnaire and VSQ9 as outcomes measures. Given the PROMIS instruments' comparability, this study provides comparative measures for studies utilizing the PROMIS-29 as an outcome measure for QoL of pregnant women receiving similar care or other care approaches.

Rothrock et al. ${ }^{44}$ examined the impact of individual and comorbid conditions and those limiting activity in a sample population with demographic characteristics matching the 2000 U.S. census figures. When compared to individuals without one chronic condition (Table 2), baseline and comparative mean $\mathrm{T}$ scores from their respondents indicate a more compromised QoL. The authors observed lower mean $\mathrm{T}$ scores in physical functioning, satisfaction in social roles, and higher mean $\mathrm{T}$ scores in fatigue and sleep disturbance. Interestingly, their chiropractic patient responders presented with lower mean $\mathrm{T}$ scores in depression and similar mean $\mathrm{T}$ scores in anxiety with no comparative values for sleep disturbance. Intuitively, this comparison may indicate that pregnant patients have a lower QoL compared to the U.S. population of individuals with one and without a chronic condition. This compromised QoL may also be a motivating factor for clinical presentation to chiropractors.

Patient satisfaction is an important measure of the quality of care as evidenced by pay-for-performance metrics such as the Centers for Medicare \& Medicaid Services reimbursements based on patient satisfaction. A person's satisfaction with their healthcare is dependent on the extent to which their general healthcare needs and condition-specific needs are met. ${ }^{45}$ Satisfied patients lead to greater compliance, a more active and continued participation in their care, as well as maintaining a specific system of care (i.e., chiropractic). ${ }^{46-48}$ Patient satisfaction surveys also benefit healthcare providers as it provides a means of assessment to improve services and optimization of health resources. ${ }^{49}$ There is no denying on the importance of conventional clinical assessments, but in situations such as those in chronically ill individuals, further clinical assessment provides no further useful information. For pregnant women, shifts to the pa- tient's viewpoint as an inevitable outcome measure are a logical measure. ${ }^{49}$ Their findings with the RAND VSQ9 to examine chiropractic patients' access and satisfaction with their care are consistent with previous findings. However, to the best of their knowledge, this is the first such reporting on patients attending care within a PBRN and the second reporting on the use of the VSQ9 among chiropractic patients. Gemmel and Hayes ${ }^{50}$ utilized the VSQ9 in 66 patients. Their VSQ9 scores ranged from $57.7 \%$ (i.e., convenience of the office location) to $95.5 \%$ (stated that they would definitely recommend chiropractic to others). Their cohort rated their visit overall at $83.3 \%$.

There is no denying that the interrelationship among health needs, patient satisfaction with their care, and their QoL is complex. It is beyond the scope of this article to address this complexity and recommend the article by Asadi-Lari et al. ${ }^{45}$ on this subject. Their study has demonstrated contemporaneous findings of high ratings of visit-specific satisfaction along with reported improvements in QoL measures. These findings are consistent with the association of satisfied healthcare needs of patients and improved QoL, as well as their satisfaction with health services and clinical effectiveness. ${ }^{45,51}$ From a chiropractic perspective, this approach to patient assessment (i.e., QoL) is coherent with a patient-centered, holistic salutogenic model of chiropractic health. ${ }^{52,53}$

There are a number of limitations with their study. First, self-reported information is associated with recall bias and possible intentional misreporting of behaviors. However, the authors mitigated against this bias by collecting data prospectively thereby asking patients to report on current behaviors, which are less susceptible to recall bias than retrospective reporting. Yet, there may be unidentifiable response bias. Second, their study subjects were chiropractic patients first and study responders second resulting in a selfselection bias. As chiropractic patients, subjective validation and expectations for clinical resolution on the part of the chiropractic clinical encounter further contribute to recall bias. The authors documented the characteristics and motivations for care in this study as a way to document and accrue evidence to help illuminate self-selection in the future. Third, insofar as they are aware, this is the first reporting on the use of the PROMIS instruments in the pregnant patient population. The PROMIS measures are domain based (i.e., generic measures) and not specific to the pregnant population. As such, the authors echo the sentiments of Mogos et al ${ }^{37}$ in that no study explored whether the PROMIS measures contained all the relevant constructs and items or whether these items have similar meaning to pregnant patients. Finally, this study was not designed to be a pure test of the causal effect of chiropractic care. As such they caution the reader in making cause and effect inferences. The authors see this as an integral part of a larger program of research on alternative treatments for pregnant women, for which longitudinal change is a critical component. Based on these findings, there is evidence to support the need for a randomized trial on chiropractic care with pregnant women. Randomized clinical trials reduce spurious causality and bias and begin to address the covariates leading to improved QoL.

Notwithstanding these limitations, there are a few methodological strengths of this study worth noting. Their sample, although a convenience sample, came from chiropractic offices across the United States and Canada. The women in the 
sample were a good sampling of women who self-select into chiropractic care in naturalistic settings. In addition, the authors used sophisticated statistical methodology to overcome limitations of traditional statistics (e.g., increased standard errors due to clustering of data and influence of confounding variables), thereby giving a purer estimate of the change in outcomes over time. Finally, the nature of their design allowed easy access to baseline and comparative measurement from many women. This demonstrates the effectiveness and efficiency of using a practice-based network as a data collection source for women involved in chiropractic care. Future researchers are encouraged to tap into similar structures to produce research.

\section{Conclusion}

The authors successfully implemented a PBRN study within a chiropractic setting and successfully implement the VSQ9 and PROMIS-29 questionnaires for pregnant patients. They found them to be highly satisfied with their visit and following a course of chiropractic care, their QoL measures improved beyond statistical significance.

\section{Author Disclosure Statement}

This study was funded by the ICPA (Media, PA) and Life West College of Chiropractic (Hayward, CA). The authors received funding from the ICPA for the preparation of the article, while J.A. received additional funding from Life West College of Chiropractic in the preparation for this article.

\section{References}

1. Martin JA, Hamilton BE, Osterman MJ, et al. Births: Final data for 2013. Natl Vital Stat Rep 2015;64:1-65.

2. Pallivalapila AR, Stewart D, Shetty A, et al. Use of complementary and alternative medicines during the third trimester. Obstet Gynecol 2015;125:204-211.

3. Birdee GS, Kemper KJ, Rothman R, Gardiner P. Use of complementary and alternative medicine during pregnancy and the postpartum period: An analysis of the National Health Interview Survey. J Womens Health (Larchmt) 2014;23:824-829.

4. Hall HG, Griffiths DL, McKenna LG. The use of complementary and alternative medicine by pregnant women: A literature review. Midwifery 2011;27:817-824.

5. Bishop JL, Northstone K, Green JR, Thompson EA. the use of complementary and alternative medicine in pregnancy: Data from the Avon Longitudinal Study of parents and children (ALSPAC). Complement Ther Med 2011;19:303-310.

6. Mitchell M. Women's use of complementary and alternative medicine in pregnancy: A search for holistic wellbeing. Women Birth 2014;27:276-280.

7. Steel A, Adams J, Sibbritt D, et al. Utilisation of complementary and alternative medicine (CAM) practitioners within maternity care provision: Results from a nationally representative cohort study of 1,835 pregnant women. BMC Pregnancy Childbirth 2012;12:146.

8. Metcalfe A, Grabowska K, Weller C, Tough SC. Impact of prenatal care provider on the use of ancillary health services during pregnancy. BMC Pregnancy Childbirth 2013;13:62.

9. Barnes PM, Bloom B, Nahin RL. Complementary and alternative medicine use among adults and children: United States, 2007. Natl Health Stat Report 2008;12:1-23.
10. Bronfort G, Haas M, Evans RL, Bouter LM. Efficacy of spinal manipulation and mobilization for low back pain and neck pain: A systematic review and best evidence synthesis. Spine J 2004;4:335-356.

11. Broom AF, Kirby ER, Sibbritt DW, et al. Use of complementary and alternative medicine by mid-age women with back pain: A national cross-sectional survey. BMC Complement Altern Med 2012;12:98.

12. Oswald C, Higgins CC, Assimakopoulos D. Optimizing pain relief during pregnancy using manual therapy. Can Fam Physician 2013;59:841-842.

13. Vowles KE, McEntee ML, Julnes PS, et al. Rates of opioid misuse, abuse, and addiction in chronic pain: A systematic review and data synthesis. Pain 2015;156:569-576.

14. Alderdice F, McNeill J, Lynn F. A systematic review of systematic reviews of interventions to improve maternal mental health and well-being. Midwifery 2013;29:389-399.

15. The International Chiropractic Pediatric Association. Online document at: www.icpa4kids.com Accessed October 15, 2017.

16. Ohm J, Alcantara J. The Webster Technique: Definition, application and implications. J Pediatr Matern Fam Health Chiropr 2012;2012:49-53.

17. International Chiropractic Pediatric Association PBRN. Online document at: http://pbrn.ahrq.gov/pbrn-registry/ international-chiropractic-pediatric-association-pbrn Accessed January 1, 2010.

18. Alcantara J, Ohm J, Kunz D. The Webster Technique: Results from a practice-based research network study. J Pediatr Matern Fam Health Chiropr Win 2012;2012:16-21.

19. Alcantara J, Ohm J, Kunz K, et al. The characterisation and response to care of pregnant patients receiving chiropractic care within a practice-based research network. Chiropr J Aust 2012;42:60-67.

20. Alcantara J, Ohm J, Kunz D. The chiropractic care of children. J Altern Complement Med 2010;16:621-626.

21. Protecting human research participants. Online document at: http://phrp.nihtraining.com/users/register.php Accessed January 1, 2010.

22. Visit-Specific Satisfaction Instrument (VSQ-9). Online document at: www.rand.org/health/surveys_tools/vsq9.html Accessed January 1, 2010.

23. Patient-Reported Outcomes Measurement Information System (PROMIS). Online document at: www.nihpromis .org/default\#4 Accessed February 1, 2010.

24. American Medical Group. Online document at www.amga .org Accessed February 28, 2015.

25. RAND Health. The 36-Item Short Form Survey from the RAND Medical Outcomes Study. Online document at: www.rand.org/health/surveys_tools/mos/mos_core_36item .html Accessed January 24, 2010.

26. Assessment Center. Online document at: www.nihpromis .org/software/assessmentcenter Accessed January 24, 2010.

27. Liu H, Cella D, Gershon R, et al. Representativeness of the Patient-Reported Outcomes Measurement Information System Internet panel. J Clin Epidemiol 2010;63:1169-1178.

28. Raudenbush SW, Bryk AS. Hierarchical Linear Models: Applications and Data Analysis Methods, 2nd ed. Thousand Oaks, CA: Sage Publications, 2002.

29. Muthén LK, Muthén BO. Mplus User's Guide, 7th ed. Los Angeles, CA: Muthen \& Muthen, 1998-2012.

30. Alcantara J, Ohm J, Alcantara J. The use of PROMIS and the RAND VSQ9 in chiropractic patients receiving care with the Webster Technique. Complement Ther Clin Pract 2016;23:110-116. 
31. Geneen LJ, Moore RA, Clarke C, et al. Physical activity and exercise for chronic pain in adults: An overview of Cochrane Reviews. Cochrane Database Syst Rev 2017;4:CD011279.

32. Gibbons R, Palmer D. Forgotten parameters of general practice: The chiropractic obstetrician. Chiropr Hist 1982;2:27-33.

33. Stuber KJ, Smith DL. Chiropractic treatment of pregnancyrelated low back pain: A systematic review of the evidence. J Manipulative Physiol Ther 2008;31:447-454.

34. Peterson CK, Mühlemann D, Humphreys BK. Outcomes of pregnant patients with low back pain undergoing chiropractic treatment: A prospective cohort study with short term, medium term and 1 year follow-up. Chiropr Man Therap 2014; 22:15.

35. George JW, Skaggs CD, Thompson PA, et al. A randomized controlled trial comparing a multimodal intervention and standard obstetrics care for low back and pelvic pain in pregnancy. Am J Obstet Gynecol 2013;208:295.e1-e7.

36. Eton DT, Bauer BA, Sood A, et al. Patient-reported outcomes in studies of complementary and alternative medicine: Problems, solutions, and future directions. Explore (NY) 2011;7:314-319.

37. Mogos MF, August EM, Salinas-Miranda AA, et al. A systematic review of quality of life measures in pregnant and postpartum mothers. Appl Res Qual Life 2013;8:219-250.

38. Alcantara J, Alcantara JD, Alcantara J. The use of validated outcome measures in the chiropractic care of pregnant patients: A systematic review of the literature. Complement Ther Clin Pract 2015;21:131-136.

39. Alcantara J, Ohm J. Improvement in quality of life for six pregnant patients undergoing chiropractic care: The promise of PROMIS. J Ped Matern Fam Health Chiropr 2013;1: $11-14$.

40. Khorsan R, Coulter ID, Hawk C, Choate CG. Measures in chiropractic research: Choosing patient-based outcome assessments. J Manipulative Physiol Ther 2008;31: 355-375.

41. Goertz CM, Pohlman KA, Vining RD, et al. Patientcentered outcomes of high-velocity, low-amplitude spinal manipulation for low back pain: A systematic review. J Electromyogr Kinesiol 2012;22:670-691.

42. HealthMeasures. Patient Reported Outcomes Measurement System. Online document at: www.healthmeasures .net/explore-measurement-systems/promis Accessed December 7, 2016.
43. Farrar JT, Young JP Jr, LaMoreaux L, et al. Clinical importance of changes in chronic pain intensity measured on an 11-point numerical pain rating scale. Pain 2001;94: $149-158$.

44. Rothrock NE, Hays RD, Spritzer K, et al. Relative to the general US population, chronic diseases are associated with poorer health-related quality of life as measured by the Patient-Reported Outcomes Measurement Information System (PROMIS). J Clin Epidemiol 2010;63:1195-1204.

45. Asadi-Lari M, Tamburini M, Gray D. Patients' needs, satisfaction, and health related quality of life: Towards a comprehensive model. Health Qual Life Outcomes 2004;2:32.

46. Guldvog B. Can patient satisfaction improve health among patients with angina pectoris? Int J Qual Health Care 1999; 11:233-240.

47. Marquis MS, Davies AR, Ware JE Jr. Patient satisfaction and change in medical care provider: A longitudinal study. Med Care 1983;21:821-829.

48. Aharony L, Strasser S. Patient satisfaction: What we know about and what we still need to explore. Med Care Rev 1993;50:49-79.

49. Leplege A, Hunt S. The problem of quality of life in medicine. JAMA 1997;278:47-50.

50. Gemmel HA, Hayes BM. Patient satisfaction with chiropractic physicians in an independent physicians' association. J Manipulative Physiol Ther 2001;24:556-559.

51. Doyle C, Lennox L, Bell D. A systematic review of evidence on the links between patient experience and clinical safety and effectiveness. BMJ Open 2013;3:e01570.

52. Gatterman MI. A patient-centered paradigm: A model for chiropractic education and research. J Altern Complement Med 1995; 1:371-386.

53. Becker CM, Glascoff MA, Felts WM, Kent C. Adapting and using quality management methods to improve health promotion. Explore (NY) 2015;11:222-228.

Address correspondence to: Joel Alcantara, DC

The International Chiropractic Pediatric Association $327 N$ Middletown Road Media, PA 19063

E-mail: dr_jalcantara@icpa4kids.com 